\title{
Assessing the scaling of the tree branch diameters frequency distribution with terrestrial laser scanning: methodological framework and issues
}

\author{
Mathieu Dassot ${ }^{1} \cdot$ Meriem Fournier $^{2} \cdot$ Christine Deleuze $^{3}$
}

Received: 5 September 2018 / Accepted: 11 June 2019 /Published online: 22 June 2019

(C) INRA and Springer-Verlag France SAS, part of Springer Nature 2019

\begin{abstract}
- Key message This article presents a specific methodology for assessing the scaling of the frequency distribution of the branch diameters within a tree from terrestrial laser scanning (TLS), using large oak trees (Quercus petraea (Matt.) Liebl.) as the case study. It emphasizes the potential of TLS in assessing branch scaling exponents and provides new insights in forest ecology and biomass allometric modelling.

- Context Many theoretical works invoke the scaling allometry of the frequency distribution of the branch diameters in tree form analyses, but testing such an allometry requires a huge amount of data that is particularly difficult to obtain from traditional measurements.

- Aims The aims of this study were (i) to clarify the theoretical and methodological basics of this allometry, (ii) to explore the possibility of establishing this allometry from terrestrial laser scanning (TLS) and geometric modelling for the solid wood structure (i.e. diameters $>7 \mathrm{~cm}$ ) of large trees, and (iii) to highlight the major methodological issues.

- Methods Three large oak trees (Quercus petraea (Matt.) Liebl.) were digitized in leaf-off conditions from multiple points of view in order to produce accurate three-dimensional point clouds. Their woody structure was modelled using geometric procedures based on polyline and cylinder fitting. The allometry was established using basics found in literature: regular sampling of branch diameters and consideration of the living branches only. The impact of including the unpruned dead branches in the allometry was assessed, as well as the impact of modelling errors for the largest branch diameter classes.

- Results TLS and geometric modelling revealed a scaling exponent of -2.4 for the frequency distribution of the branch diameters for the solid wood structure of the trees. The dead branches could highly influence the slope of the allometry, making essential their detection in TLS data. The accuracy of diameter measurement for the highest diameter classes required particular attention, slight errors in these classes having a high influence on the slope of the allometry.

- Conclusion These results could make it possible automated programs to process large numbers of trees and, therefore, to provide new insights in assessing forest structure, scaling, and dynamics for various environments in the context of climate change.
\end{abstract}

Keywords Allometry $\cdot$ Pipe model $\cdot$ Terrestrial LiDAR $\cdot$ Geometric modelling $\cdot$ Cylinder fitting $\cdot$ Tree architecture

Handling Editor: Barry Alan Gardiner

Contribution of the co-authors MD developed the methodology, processed and analysed the data and wrote the manuscript. MF and CD contributed to the final version of the manuscript. CD managed the main funding project and proposed this work.

Mathieu Dassot

mathieu.dassot@gmail.com

1 EcoSustain, Environmental Engineering Office, Research and Development, 31, rue de Volmerange, F-57330 Kanfen, France

2 Université de Lorraine, AgroParisTech, INRA, UMR Silva, F-54000 Nancy, France

3 ONF, RDI, F-39100 Dole, France

\section{Introduction}

Allometric research has often used scaling relationships and power-laws (Marquet et al. 2005; Warton et al. 2006) to investigate tree form and growth patterns (Niklas 1994; West et al. 1999). The pipe model theory (Shinozaki et al. 1964a), describing the woody structure of the tree as a ramified system of successive pipe units, in which the cross-sectional area of a woody stem is proportional (i) to the amount of leaves it supports, and (ii) to the sum of the cross-sectional areas of its daughter-stems, has been strengthened in general theories of structural-functional plant design (Enquist 2002). The pipe 
model structural law has been widely used and debated in the fields of tree growth and form (Valentine 1985; Chiba 1990, 1991; Berninger et al. 2005; Dahle and Grabosky 2009), or tree physiology and ecology (Ewers and Zimmermann 1984a, b; Tyree and Ewers 1991; West et al. 1999, 2009; Bentley et al. 2013; Eloy et al. 2017).

More especially, the pipe model theory made it possible to assess the scaling allometry (i.e. the log-log linear relationship) of the frequency distribution of the branch diameters within a tree (Shinozaki et al. (1964b), Figure 4 of the original paper). For the species considered, the frequency of branch diameter decreased as -2 or -1.5 power when branch diameter increased. In a recent and comprehensive review of the pipe model theory, Lehnebach et al. (2018) emphasized the poor theoretical basis of this popular and widely used scaling law in the light of modern biology and process-based models (Le Roux et al. 2001; Price et al. 2013; Eloy et al. 2017). However, the pipe model and more generally allometric laws (see Niklas (1994)) are powerful tools to describe general relationships between organ and body size in trees. They allow to investigate from simple tree ring or trunk measurements challenging basic research questions about ecosystem and tree functioning (e.g. Stephenson et al. (2014) or Mencuccini et al. (2019), which emphasized that "developing larger datasets of the variability of stem cross-sectional areas within trees is a priority to allow scaling of Huber value from branches to trees"), especially in the context of global change (Ibanez et al. 2016; Babst et al. 2018). Such an interest of allometries is well known since the model of West, Brown and Enquist (WBE) (West et al. 1999). Obviously, checking the validity of scaling laws for the biggest trees, which generate important changes and fluxes of biomass, carbon and water, remains a challenge because it requires detailed datasets about trunk and branch sizes within trees, which are scarce, given the time-consuming measurement of the tree branching structure with traditional methods. The recent development of terrestrial laser scanning (TLS) technology in forest science could, however, fill this gap in branching data.

TLS is a remote sensing technique that makes possible the non-destructive three-dimensional (3D) digitisation of objects or scenes, providing their virtual representation as a dense 3D point cloud. Adapted modelling steps then allow the extraction of the metrics of the objects from the 3D virtual scene. During the past 15 years, TLS was successfully applied to measuring forest structure with the aim of forest inventory (stem diameter, height and volume) and canopy measurements (leaf area index, gap fraction), as reviewed in Dassot et al. (2011) and Liang et al. (2016). TLS also made possible the measurement of the branching structure of standing trees in the forest environment, with good estimates of volume, biomass or branch size distribution (Bucksch and Fleck 2011; Dassot et al. 2012; Raumonen et al. 2013; Calders et al. 2015). Such a literature suggests that TLS could be a promising technique in forest ecology, especially to refine individual scaling allometries requiring a high level of information about the branching structure of trees (Malhi et al. 2018; Lau et al. 2019).

The objectives of this study are as follows:

1. To clarify the theoretical and methodological basics necessary in establishing the scaling allometry of the frequency distribution of the branch diameters, starting from the work of Shinozaki et al. (1964b);

2. To establish this allometry for the solid wood structure (i.e. diameters $>7 \mathrm{~cm}$ ) of some large trees, using a specifically developed methodology coupling TLS measurements to geometric modelling procedures allowing for detailed branch diameter profiling;

3. To assess the influence of the unpruned dead branches (which logically have to be excluded) on the allometry, whose detection in TLS data is often problematic;

4. To assess the influence of errors in diameter measurement for the largest diameter classes, whose influence on the slope of the allometry can be significant due to the logarithmic scales.

Based on these points, the biological and methodological findings of the study will be discussed.

\section{Material and methods}

\subsection{Tree sampling}

Three large oak trees (Quercus petraea (Matt.) Liebl.) were selected in a coppice with standards stand located in the state forest of Champenoux, in Northeast France $\left(48^{\circ} 41^{\prime} 57^{\prime \prime} \mathrm{N}, 6^{\circ}\right.$ $\left.21^{\prime} 15^{\prime \prime} \mathrm{E}\right)$. These trees were more than 200 years old, higher than $25 \mathrm{~m}$ with a diameter at breast height between 65 and $95 \mathrm{~cm}$ (see Table 1) and presented large branching systems with several unpruned dead branches at the crown base.

\subsection{Tree digitisation and point cloud registration}

Terrestrial laser scanners make possible the non-destructive three-dimensional (3D) digitisation of objects or physical scenes. The digitisation relies on a thin laser beam that is

Table 1 Characteristics of the measured trees

\begin{tabular}{llll}
\hline Tree & $\begin{array}{l}\text { Age } \\
\text { (years) }\end{array}$ & $\begin{array}{l}\text { Diameter at breast } \\
\text { height }(\mathrm{cm})\end{array}$ & $\begin{array}{l}\text { Main stem } \\
\text { length }(\mathrm{m})\end{array}$ \\
\hline A & 218 & 93.9 & 28.32 \\
B & 218 & 76.7 & 25.90 \\
C & 219 & 65.9 & 27.96 \\
\hline
\end{tabular}


deflected by a rotating mirror in millions of directions and scans the scene. For each direction, the laser beam is backscattered by the encountered target. The returning signal allows the scanner to compute a distance, which is coupled to the azimuth-zenith information provided by the mirror to record a 3D point at the location of the interception. Millions of points are therefore recorded over the surface of the objects and constitute a 3D point cloud representing them. Since a scanner only digitizes the exposed side of the objects, several scans have to be performed around them to allow for their complete digitisation. Moreover, since point spacing (i.e. the distance between adjacent points) increases with distance to the scanner, scanning settings must be adapted to the size and complexity of the objects. The 3D representation of the scene then requires $3 \mathrm{D}$ modelling steps to provide the metrics of the objects (Dassot et al. 2011).

The three oaks were individually digitized in December 2009, in leafless conditions. TLS measurements were performed with a phase-based FARO Photon 120 scanner, with settings allowing for high measurement quality and high point cloud density (Table 2). Four scans were performed around each tree. FARO Scene 4.5 software was used to merge the four scans (having their own coordinate system) into one coregistered point cloud, based on reference targets placed around the tree base prior to scanning. This scanning protocol made it possible to obtain a detailed $3 \mathrm{D}$ representation of the woody structure of the trees (Fig. 1).

\subsection{D modelling of the solid wood structure}

The solid wood structure of each tree (i.e. the woody axes of more than $7 \mathrm{~cm}$ in diameter) was modelled using geometric fitting procedures in PolyWorks software (PolyWorks, InnovMetric Software Inc.), as described in Dassot et al. (2012). To summarize, the 3D modelling method relied on two steps. As a first step, a polyline (i.e. a succession of 3D points with particular 3D coordinates) was manually fitted on each woody axis of the tree, providing its spatial position and its curved length. Following fitting, the polyline points were resampled every $25 \mathrm{~cm}$ to transform the polyline into a sequence of 25-cm-long segments. The polylines formed the 3D skeleton of the tree.

The second step was the assessment of diameter variation along each woody axis. A circular cylinder was fitted on the data points selected within a specified distance from each polyline segment. The result was a sequence of cylinders following the point cloud of the tree axis (one cylinder per $25-\mathrm{cm}$ segment). This procedure allowed the cylinders to be automatically fitted every $25 \mathrm{~cm}$ and, therefore, diameters to be sampled every $25 \mathrm{~cm}$ (Fig. 2). Each diameter was affected to the nearest polyline point. A careful inspection of the tree model was then carried out to visually detect unrealistic cylinders. The unrealistic cylinders were either individually corrected (if possible), or removed. In case of point cloud discontinuity (due to occlusion), no cylinder could be fitted. The missing diameters were therefore assessed from linear interpolation between two well-fitted cylinders, or extrapolated in the case of missing proximal diameters (branch insertion).

The main stem of each tree was easily identified within the crown as the thickest woody axis continuing the trunk after its successive ramifications. In a previous study, the cylinder model of each tree was validated by comparing it with destructive measurements of wood volume and length on the felled tree (Dassot et al. 2012).

\subsection{Detection of the unpruned dead branches}

The allometry of the frequency distribution of branch diameters only considers the living branches. In other words, the dead branches that have not been naturally pruned have to be excluded from the allometry and, therefore, to be identified in the tree point cloud. Since our scanning protocol, coupling
Table 2 Laser scanner specifications and settings for data acquisition

\begin{tabular}{lll}
\hline FARO Photon 120 & Device specifications & Experiment settings \\
\hline Rangefinder & Phase-shift & - \\
Wavelength & $785 \mathrm{~nm}$ & - \\
Return type & Single return & - \\
Measurement range & $0.6-120 \mathrm{~m}$ & - \\
Range accuracy & $\pm 2 \mathrm{~mm}($ at $25 \mathrm{~m})$ & - \\
Beam diameter at exit/beam divergence & $3.3 \mathrm{~mm} / 0.16 \mathrm{mrad}$ & - \\
V $\times$ H field-of-view & up to $320^{\circ} \times 360^{\circ}$ & $320^{\circ} \times 360^{\circ}$ \\
Horizontal scanning resolution & up to $40,000 \mathrm{pts} / 360^{\circ}$ & $10,000 \mathrm{pts} . / 360^{\circ}$ \\
Point spacing at $10 \mathrm{~m}$ & up to $1.5 \mathrm{~mm}$ & $6 \mathrm{~mm}$ \\
Acquisition rate & $122,000-976,000 \mathrm{pts} . / \mathrm{s}$ & $122,000 \mathrm{pts} . / \mathrm{s}$ \\
Single scan duration & $7 \mathrm{~s}-1 \mathrm{~h} 49 \mathrm{~min}$ & $6 \mathrm{~min} 49 \mathrm{~s}$ \\
Weight including battery & $20 \mathrm{~kg}$ & - \\
\hline
\end{tabular}



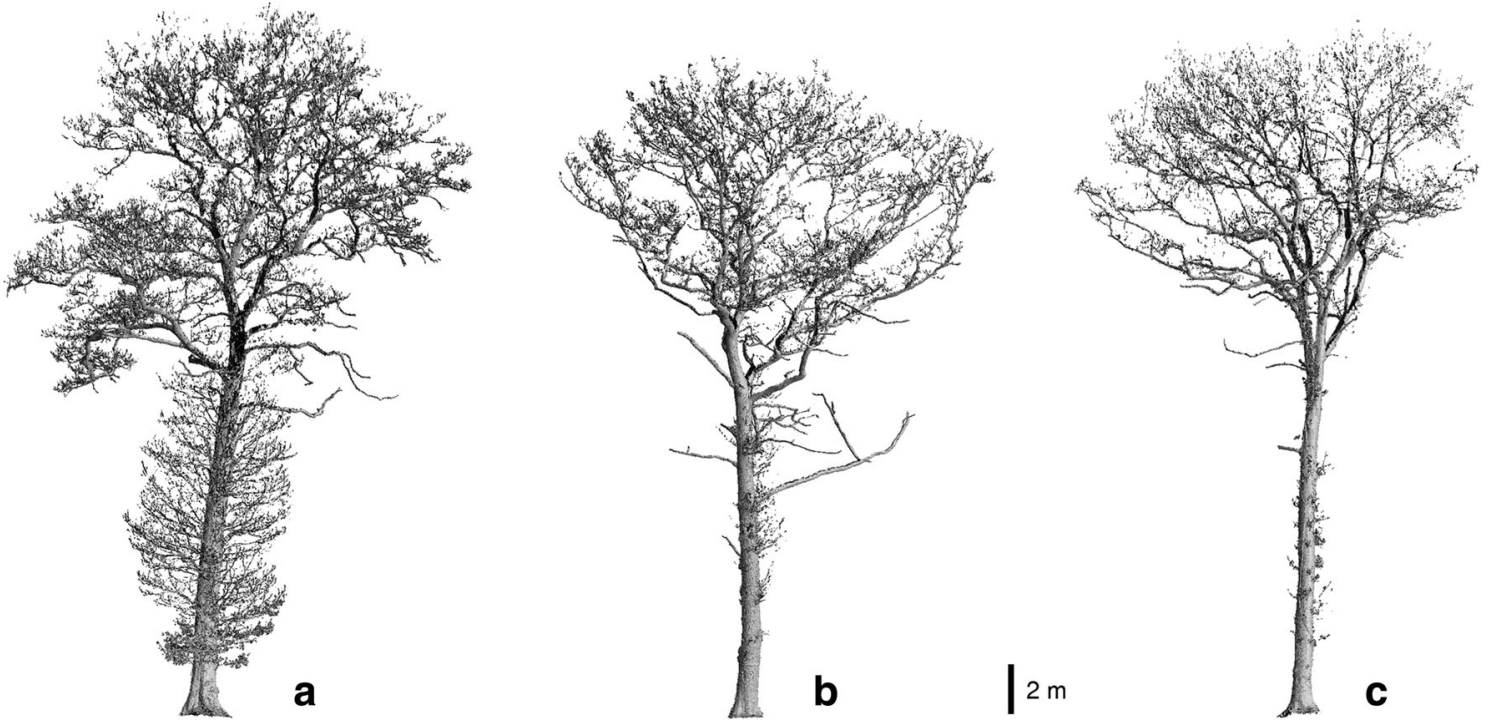

Fig. 1 Lateral view of the point clouds of the three oaks, illustrating the detailed description of their woody structure

high spatial resolution to long acquisition time, was able to capture the thin branches of the trees, the unpruned dead branches were visually identified as the branches that did not present thin point clouds (i.e. the last branch orders such as twigs or shoots) and thin ramifications. In addition, these dead branches always presented a large distal diameter corresponding to a breakage zone (Fig. 3).

\subsection{Focus on the accuracy of branch diameter measurement for the largest diameter class}

Since the scaling allometry of the frequency distribution of branch diameters uses logarithmic scales, the largest (i.e. the rarest) branch diameters heavily weigh on the slope of the relationship. Therefore, high accuracy and reliability of diameter measurement (i.e. cylinder fitting) are critical for the largest diameter classes to avoid too much bias on the slope of the relationship. Particular attention was therefore paid on the

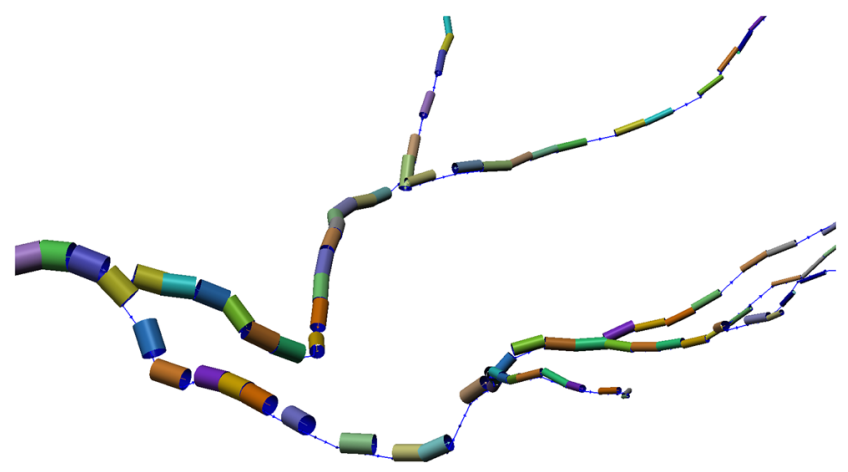

Fig. 2 Detail from a part of the final tree model, which is composed by sequences of cylinders fitted on the tree point cloud (not displayed) following the previously fitted polylines largest branch diameters during the verification of each tree model, such diameters being typically found at the insertion of the largest branches.

An incorrect cylinder was found at the insertion of the largest branch of tree B. The first cylinder of the branch was partly fitted on points belonging to the main stem and led to a cylinder of overestimated diameter, which was moreover assigned to the second polyline point. The diameter for the first point of the polyline was extrapolated (and, therefore, also overestimated) from the second and the third points, in accordance with the modelling procedure. The manual selection of the data points of the proximal zone of the branch made it possible to fit a corrected cylinder for the first point of the polyline.

\subsection{Data analysis}

Data analysis was performed with R 3.3.2 (R Core Team 2016) as follows:

1. Reference allometry. The reference allometry of the frequency distribution of branch diameters was established for each individual tree according to the basics of Shinozaki et al. (1964b): consideration of all aerial woody axes other than the main stem and regular sampling of the branch diameters. Since the pipemodel is reliable only for the living branches, we also excluded the unpruned dead branches from the reference allometry. The only difference was the step used for diameter sampling: every $25 \mathrm{~cm}$ in our modelling procedure, whereas it was every $10 \mathrm{~cm}$ in Shinozaki et al. (1964b). The branch diameters given by the 3D tree mock-up were grouped into $1-\mathrm{cm}$ diameter classes. The frequency of occurrence of each diameter 
Fig. 3 Visual comparison between a living branch (a) and an unpruned dead branch (b). The dead branch is identified from the absence of thin twigs
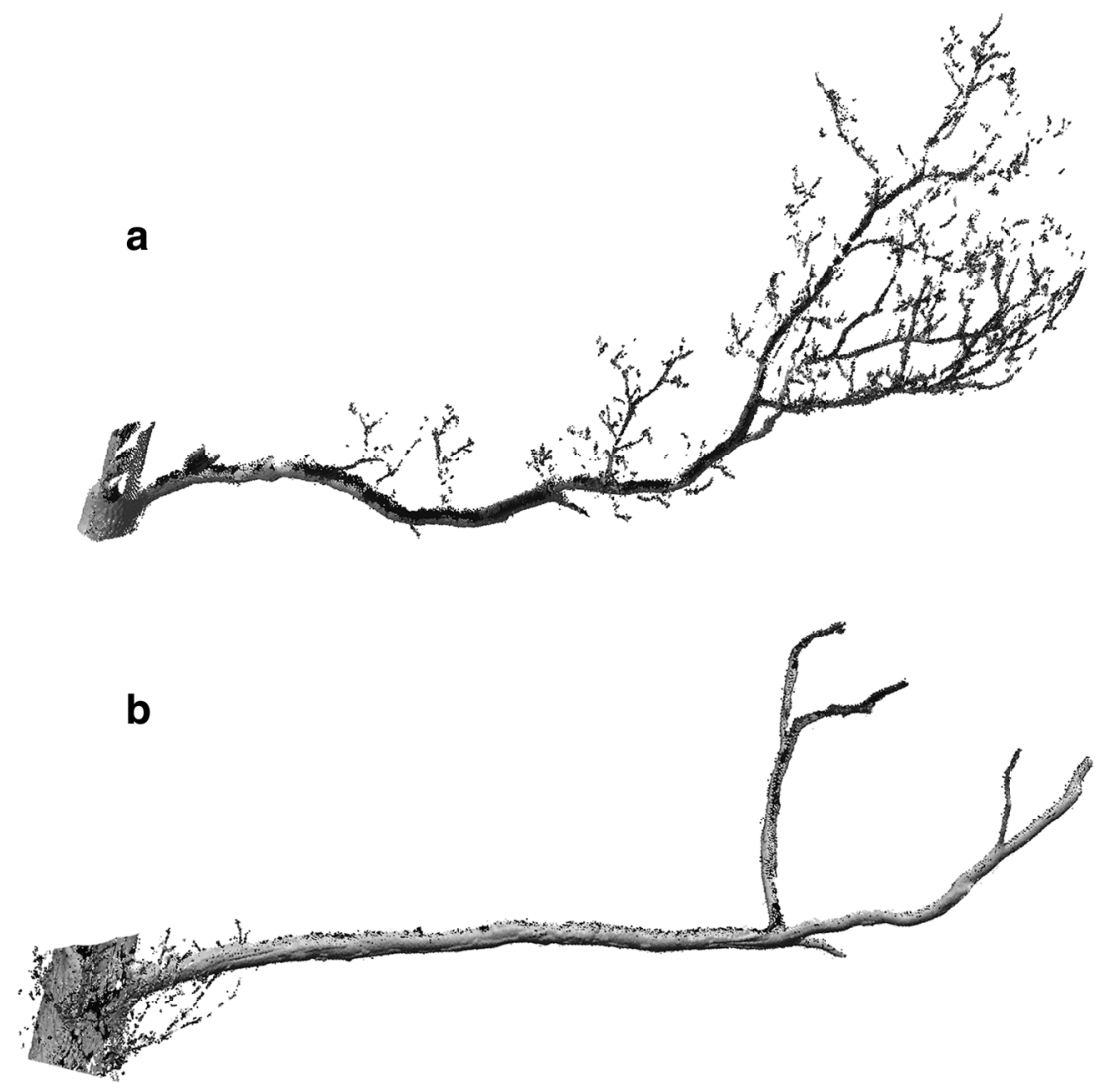

class was calculated. For each tree, diameter class frequency was plotted versus diameter class on a graph with logarithmic scales (log-log graph) and an ordinary least square (OLS) linear regression with $t$ test was fitted to assess the slope (i.e. the allometric scaling exponent) of the relationship

2. Allometry including the unpruned dead branches. To assess their possible influence on the slope of the allometry,
Oak A

$e=-2.41$

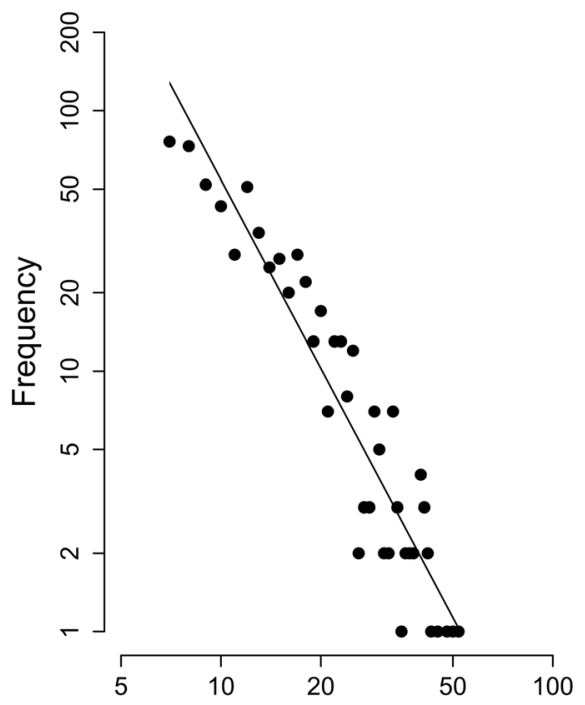

Oak B

$e=-2.37$

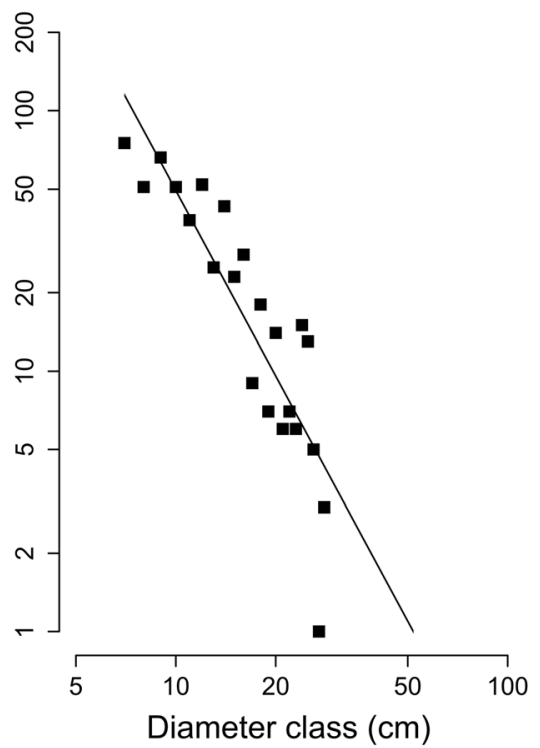

Oak C $e=-2.44$

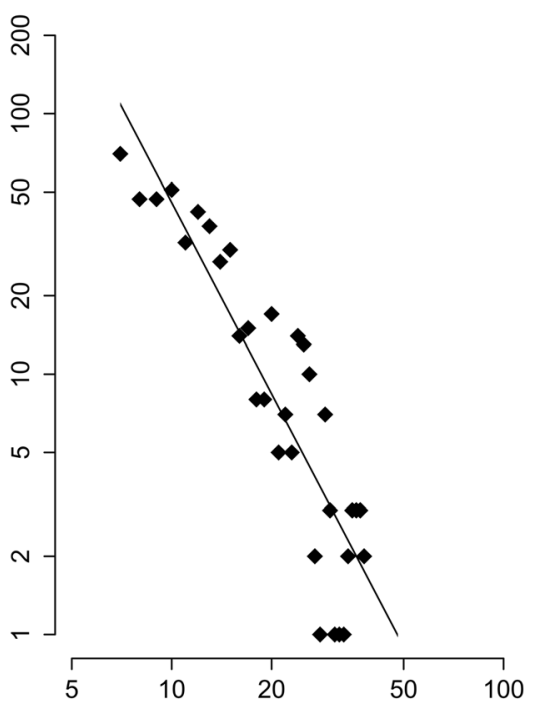

Fig. 4 Reference scaling allometry of the frequency distribution of branch diameters. Diameter class frequency is plotted versus diameter class on logarithmic scales and the scaling exponent is computed from an ordinary least square (OLS) linear regression 
the diameters of the unpruned dead branches were then added to the diameters of the living branches. Again, an OLS linear regression was fitted to assess the shift in the allometric scaling exponent caused by the dead branches.

3. Allometry including previously detected slight errors in diameter measurement for the largest diameter classes. The wrong cylinder detected at the insertion of the largest branch during the verification of tree B allowed us to assess the influence of such a modelling error on the allometry. A comparison between the two allometries (with and without diameter error at the insertion of the largest branch) was performed for tree B.

\section{Results}

\subsection{Reference allometry of the frequency distribution of branch diameters}

For each tree a log-log-linear relationship between diameter class frequency and diameter class was found to be significant $\left(t=-17.34, P<0.001, R^{2}=0.89\right.$ for tree $\mathrm{A}, t=-8.01$, $P<0.001, R^{2}=0.75$ for tree $\mathrm{B} ; t=-10.93, P<0.001, R^{2}=$ 0.79 for tree $C$ ), as presented in Fig. 4 . The data plotted in the logarithmic domain however revealed a slight curvilinear shape. The allometric scaling exponent (i.e. the slope of the relationship) was very close for the three trees and was respectively $-2.41,-2.37$ and -2.44 for tree $\mathrm{A}, \mathrm{B}$ and $\mathrm{C}$. The intercept of the relationship was also very close and was respectively 4.14, 4.06 and 4.1 for tree A, B and C.

\subsection{Allometry including the diameters of the unpruned dead branches}

The log-log-linear relationship between diameter class frequency and diameter class was also significant when including the diameters of the unpruned dead branches $(t=-17.33$, $P<0.001, R^{2}=0.89$ for tree A; $t=-8.67, P<0.001, R^{2}=$ 0.78 for tree $\mathrm{B} ; t=-11.21, P<0.001, R^{2}=0.80$ for tree $\mathrm{C}$ ), as presented in Fig. 5. The scaling exponent was close for the three trees but lower than for the reference allometry, i.e. $2.56,-2.62$ and -2.51 for tree A, B and C, respectively. The intercept of the relationship was very close and was respectively $4.4,4.45$ and 4.2 for tree A, B and C.

\subsection{Allometry including slight errors in diameter measurement for the largest diameter classes}

Specifically for tree B, the log-log-linear relationship between diameter class frequency and diameter class was also significant when including slight errors in diameter measurement for the largest diameter classes $(t=-8.17$, $\left.P<0.001, R^{2}=0.75\right)$, as presented in Fig. 6 . The scaling exponent was therefore -2.61 , i.e. lower than for the reference allometry. The intercept of the relationship was 4.32 .
Oak A

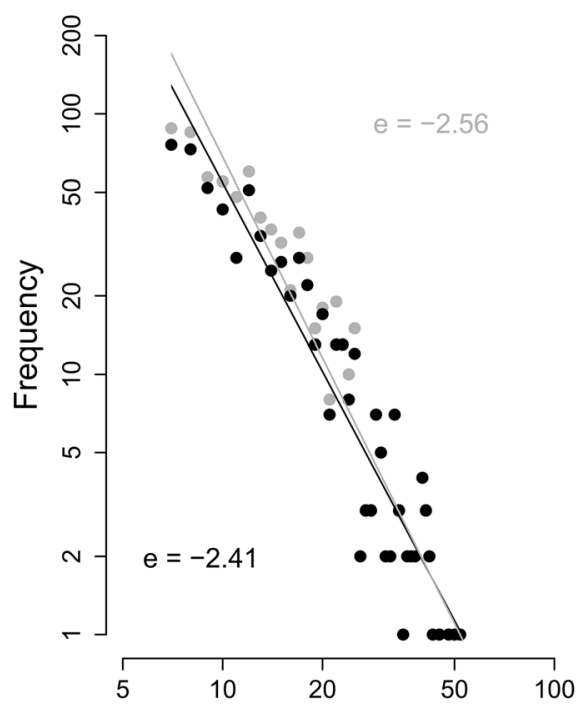

Oak B

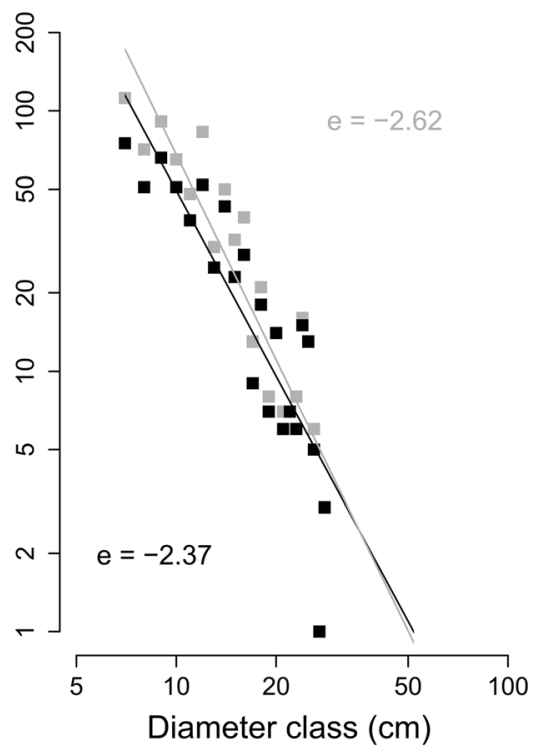

Oak C

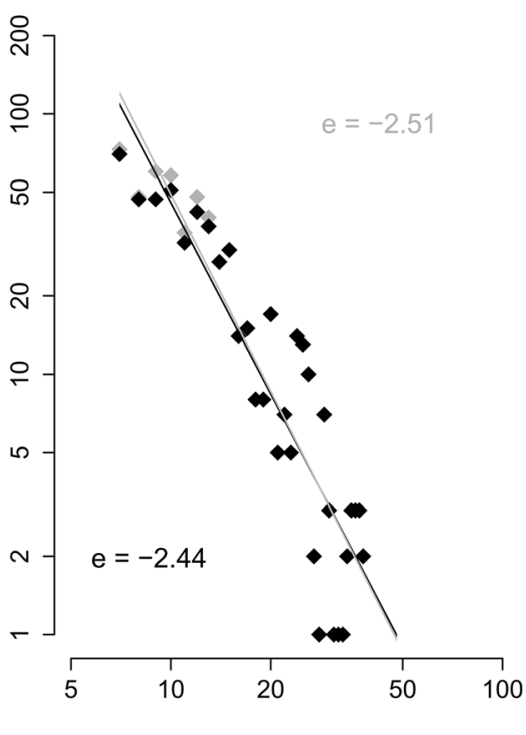

Fig. 5 Comparison between the reference allometry (black dots and black line) and the allometry including the unpruned dead branches (grey dots and grey line) 


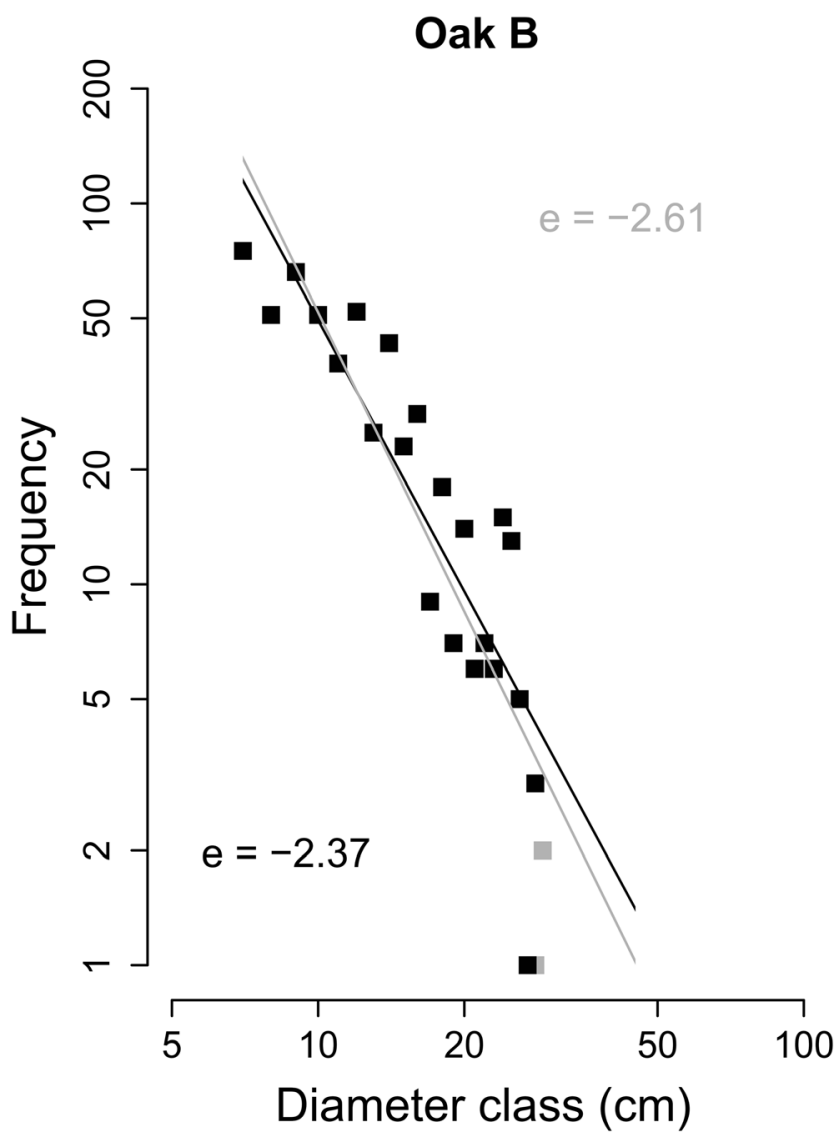

Fig. 6 Comparison between the reference allometry (black dots and black line) and the allometry including slight errors in diameter measurement for the largest branch diameter classes (grey dots and grey line)

\section{Discussion}

\subsection{Scaling of the frequency distribution of the branch diameters}

To our knowledge, this study is one of the few to investigate the scaling allometry of the frequency distribution of branch diameters from experimental data, and the first one focusing on such large trees (i.e. on such a large range of branch diameters). It reveals a similar scaling allometry for the three oak trees selected. Both the scaling exponents and intercepts are extremely close among the trees, indicating a close similarity in their branching systems. This similarity is not surprising, since the trees were of the same species, the same age and grew in the same place under similar site conditions and management. Branch diameter frequency thus scales as the -2.4 power of branch diameter for the solid wood structure of the three oaks. This scaling exponent is slightly lower than those obtained in Shinozaki et al. (1964b) for smaller trees of other species. Even if the allometry can be modelled successfully with a log-log-linear regression, the plotted point cloud actually presents a slightly curvilinear shape. Indeed, branch diameter frequency is always lower than the value predicted by the regression line for the largest diameter classes due to the important taper of branches in their proximal region (Shinozaki et al. 1964b). This phenomenon is all the more pronounced when the selected trees are particularly large.

Therefore, the law fitted on our few large trees is very close to the usual pipe model theory, although biologically, one could expect significant differences since several quantitative vascular parameters that disturb the pipe model allometries depend on ontogeny or size (Lehnebach et al. 2018). The trees we studied are really big and old with some symptoms of senescence, so such a stable allometry is really surprising and suggests other underlying biological processes than hydraulic conservation (see the discussion of Lehnebach et al. (2018)).

Keeping in mind that branches thinner than $7 \mathrm{~cm}$ and epicormic shoots were not measured in our TLS method, if trees really fit so well with the pipe model theory, we could estimate, from the slight differences observed, the biomass of the thinner branches, whose description quality in TLS data is often poor and leads to erroneous cylinders (Hackenberg et al. 2015a; Lau et al. 2018).

\subsection{On the essential detection of the unpruned dead branches}

Including the unpruned dead branches increased the frequency of occurrence of the low and middle diameter classes, accentuating the slope of the allometry (i.e. decreasing the scaling exponent). The shift in the slope of the allometry can be important enough (see tree B, Fig. 5) to make essential the detection of the unpruned dead branches in TLS data.

Unpruned dead branches are often reported to be difficult to detect in 3D point clouds and a source of bias, especially in assessing the height of the canopy base from TLS (García et al. 2011). Distinguishing dead from living branches would require intensity data from particular spectral bands (Kankare et al. 2013), which are not used in conventional terrestrial laser scanners at the moment. In our study, however, the dead branches were easily identified from visual features, i.e. the absence of thin twigs, which was always coupled to the presence of a large distal diameter due to branch breakage.

Lastly, allometric laws are based on the assumption of steady state or optimal design. Therefore, trees recently disturbed (for example by massive branch breakage after a strong wind event or massive branch death after pest attack) are expected to be outliers in the general law. It is not the case in our sample, where branches naturally died during growth.

\subsection{Potential and limitations of TLS and geometric modelling}

This study used a methodology that has already been successfully applied to architectural measurements and volume 
estimates for branches with a diameter of more than $7 \mathrm{~cm}$ (Dassot et al. 2010, 2012). This methodology relies on a relatively light scanning protocol based on restrained resolution (point spacing of $6 \mathrm{~mm}$ at $10 \mathrm{~m}$ from the scanner) and acquisition time ( $7 \mathrm{~min}$ per scan) from four points-of-view, which allows for a high level of detail about the tree structure of more than $7 \mathrm{~cm}$ in diameter with a reduced level of noise in the point clouds. Measuring thinner branches (down to $4 \mathrm{~cm}$ in diameter, for example) would be conceivable if moving to the higher resolution (point spacing of $3 \mathrm{~mm}$ at $10 \mathrm{~m}$ ), which records four times more data points, but in turn multiplies scanning duration by four (for the same scanning quality/noise control settings) and drastically increases processing times. Our methodology also uses circular cylinders, which have been the most commonly used geometric shape for modelling branches (Thies et al. 2004; Raumonen et al. 2013; Hackenberg et al. 2014). The circular cylinder was reported to be more robust and less sensitive to noise and data quality than more complex shapes such as the elliptic cylinder, the polygonal cylinder, the truncated circular cone or the spline curve (Pfeifer and Winterhalder 2004; Akerblom et al. 2015), making it particularly adapted for modelling branches, which are only partially described in TLS data due to occlusion.

The modelling method however presents some limitations. The first limitation concerns the accuracy of diameter measurement for the largest diameter classes. Using 25-cm-long cylinders makes it possible to sample branch diameter at $25-\mathrm{cm}$ intervals, whereas it was $10 \mathrm{~cm}$ in Shinozaki et al. (1964b). Although 25-cm-long cylinders are able to assess branch diameters for the major part of the tree branching system, it does not allow for the accurate description of the proximal region of branches with pronounced taper, merging several diameter classes into one. Given the high sensitivity of the scaling allometry of branch diameter frequency to the accuracy of diameter measurement for the largest diameter classes (e.g. tree B), using shorter cylinders would be more appropriate. In return, it would increase the rate of unrealistic cylinders (wrong orientation and wrong diameter) for the rest of the branches. Anyway, the careful verification of the cylinders for the largest diameter classes remains essential, since some change in the frequency of occurrence for these classes can highly impact the slope of the allometry due to the logarithmic scales.

The second limitation concerns the assessment of the missing diameters. The missing diameters are linearly interpolated between two well-fitted cylinders and do not correspond to direct cylinder fitting. This linear interpolation does not follow the real branch diameter profile and can, therefore, slightly influence the repartition of diameters among the diameter classes. Interpolating the missing cylinders is however unavoidable to overcome the negative effects of occlusion (Raumonen et al. 2013; Hackenberg et al. 2014).

\subsection{Automation of 3D modelling}

Assessing such a complex allometry as the frequency distribution of the branch diameters requires a particularly detailed description of the woody structure of the tree which imposes a lot of constraints on 3D modelling. It requires the modelling method to be adaptable and versatile enough (i) to be able to sample diameters at fine and regular intervals, and (ii) to allow for the case-by-case verification and correction of visually unrealistic cylinders in specific parts of the tree. Even if these requirements are met by the method of Dassot et al. (2012), this method is only partially automated, making it too timeconsuming to be performed on a large number of trees.

In the last few years fully automated programs allowing for accurate wood volume estimates from TLS measurements and cylinder-based quantitative structure modelling have emerged (Hackenberg et al. 2015b; Raumonen et al. 2013). Applying them to the scaling of the frequency distribution of the branch diameters would require further development to allow for the configuration of 3D modelling (especially in specifying the interval for branch diameter measurement) and the manual correction of the tree model in specific parts (e.g. branch insertion). Moreover, these programs can include allometric corrections to improve the cylinder model, which generally improve volume estimates, but are not desirable when the aim is precisely to assess an allometric relationship. Comparing automated 3D reconstructions using an appropriate framework (Boudon et al. 2014) could also be considered for such a biological application.

\section{Conclusion}

This study presented an innovative application of groundbased remote sensing and 3D modelling, providing new insights in forest ecology and for developing biomass allometric models. It demonstrated the potential of TLS and geometric modelling in assessing a scaling allometry that requires extensive information about the branching system of forest trees, highlighting the key points to be observed and the major issues to overcome. Taking into consideration these findings would make automated programs able to establish detailed allometries for large numbers of trees, with a high level of confidence in the absence of reference data. TLS would therefore become a powerful tool to refine scaling theories and laws for trees of variable species, age and size, as well as their variation with ontogeny or climate change in diverse forest environments. Given the fast development of ground-based remote sensing technologies in the forest science worldwide, there is no doubt that allometric research requiring a high level of detail about the tree structure will greatly benefit from TLS in the near future. 
Funding This study used TLS data from the Ph.D of Mathieu Dassot, which was funded by the French National Research Agency (ANR) through the EMERGE project (ANR BIOENERGIES 2008 BIOE-003), the French Forestry Office (ONF) through the Modelfor contract (20052010), the French National Forest Inventory (IFN) through the contract 2008-CER-4148 and FEDER Lorraine (2007-2013).

Data availability Dataset available from the corresponding author on reasonable request.

\section{Compliance with ethical standards}

Conflict of interest The authors declare that they have no conflict of interest.

\section{References}

Akerblom M, Raumonen P, Kaasalainen M, Casella E (2015) Analysis of geometric primitives in quantitative structure models of tree stems. Remote Sens 7:4581-4603

Babst F, Bodesheim P, Charney N, Friend AD, Girardin MP, Klesse S, Moore DJP, Seftigen K, Björklund J, Bouriaud O, Dawson A, DeRose RJ, Dietze MC, Eckes AH, Enquist B, Frank DC, Mahecha MD, Poulter B, Record S, Trouet V, Turton RH, Zhang Z, Evans MEK (2018) When tree rings go global: challenges and opportunities for retro- and prospective insight. Quat Sci Rev 197:120. https://doi.org/10.1016/j.quascirev.2018.07.009

Bentley LP, Stegen JC, Savage VM, Smith DD, von Allmen EI, Sperry JS, Reich PB, Enquist BJ (2013) An empirical assessment of tree branching networks and implications for plant allometric scaling models. Ecol Lett 16:1069-1078. https://doi.org/10.1111/ele.12127

Berninger F, Coll L, Vanninen P, Mäkelä A, Palmroth S, Nikinmaa E (2005) Effects of tree size and position on pipe model ratios in scots pine. Can J For Res 35:1294-1304. https://doi.org/10.1039/X05-055

Boudon F, Preuksakarn C, Ferraro P, Diener J, Nacry P, Nikinmaa E, Godin C (2014) Quantitative assessment of automatic reconstructions of branching systems obtained from laser scanning. Ann Bot 114:853-862. https://doi.org/10.1093/aob/mcu062

Bucksch A, Fleck S (2011) Automated detection of branch dimensions in woody skeletons of fruit tree canopies. Photogramm Eng Remote Sens 77:229-240

Calders K, Newnham G, Burt A, Murphy S, Raumonen P, Herold M, Culvenor D, Avitabile V, Disney M, Armston J, Kaasalainen M (2015) Nondestructive estimates of above-ground biomass using terrestrial laser scanning. Methods Ecol Evol 6:198-208. https:// doi.org/10.1111/2041-210X.12301

Chiba Y (1990) Plant form analysis based on the pipe model theory I. A statistical model within the crown. Ecol Res 5:207-220. https://doi. org/10.1007/BF02346992

Chiba Y (1991) Plant form based on the pipe model theory II. Quantitative analysis of ramification in morphology. Ecol Res 6: 21-28. https://doi.org/10.1007/BF02353867

Dahle GA, Grabosky JC (2009) Review of literature on the function and allometric relationships of tree stems and branches. J Arboric 35:311

Dassot M, Barbacci A, Colin A et al (2010) Tree architecture and biomass assessment from terrestrial LiDAR measurements: a case study for some beech trees (Fagus sylvatica). Freiburg, Germany, pp 206-215

Dassot M, Constant T, Fournier M (2011) The use of terrestrial LiDAR technology in forest science: application fields, benefits and challenges. Ann For Sci 68:959-974. https://doi.org/10.1007/s13595011-0102-2

Dassot M, Colin A, Santenoise P, Fournier M, Constant T (2012) Terrestrial laser scanning for measuring the solid wood volume, including branches, of adult standing trees in the forest environment. Comput Electron Agric 89:86-93. https://doi.org/10.1016/j. compag.2012.08.005

Eloy C, Fournier M, Lacointe A, Moulia B (2017) Wind loads and competition for light sculpt trees into self-similar structures. Nat Commun 8:1014

Enquist BJ (2002) Universal scaling in tree and vascular plant allometry: toward a general quantitative theory linking plant form and function from cells to ecosystems. Tree Physiol 22:1045-1064

Ewers FW, Zimmermann MH (1984a) The hydraulic architecture of eastern hemlock (Tsuga canadensis). Can J Bot 62:940-946. https://doi. org/10.1139/b84-133

Ewers FW, Zimmermann MH (1984b) The hydraulic architecture of balsam fir (Abies balsamea). Physiol Plant 60:453-458. https://doi.org/ 10.1111/j.1399-3054.1984.tb04911.x

García M, Danson FM, Riaño D, Chuvieco E, Ramirez FA, Bandugula V (2011) Terrestrial laser scanning to estimate plot-level forest canopy fuel properties. Int J Appl Earth Obs Geoinformation 13:636-645. https://doi.org/10.1016/j.jag.2011.03.006

Hackenberg J, Morhart C, Sheppard J, Spiecker H, Disney M (2014) Highly accurate tree models derived from terrestrial laser scan data: a method description. Forests 5:1069-1105. https://doi.org/10.3390/ f5051069

Hackenberg J, Wassenberg M, Spiecker H, Sun D (2015a) Non destructive method for biomass prediction combining TLS derived tree volume and wood density. Forests 6:1274-1300. https://doi.org/10. 3390/f6041274

Hackenberg J, Spiecker H, Calders K, Disney M, Raumonen P (2015b) SimpleTree-an efficient open source tool to build tree models from TLS clouds. forests 6:4245-4294. https://doi.org/10.3390/f6114245

Ibanez I, Zak DR, Burton AJ, Pregitzer KS (2016) Chronic nitrogen deposition alters tree allometric relationships: implications for biomass production and carbon storage. Ecol Appl 26:913-925. https:// doi.org/10.1890/15-0883

Kankare V, Holopainen M, Vastaranta M, Puttonen E, Yu X, Hyyppä J, Vaaja M, Hyyppä H, Alho P (2013) Individual tree biomass estimation using terrestrial laser scanning. ISPRS J Photogramm Remote Sens 75:64-75. https://doi.org/10.1016/j.isprsjprs.2012.10.003

Lau A, Bentley LP, Martius C, Shenkin A, Bartholomeus H, Raumonen P, Malhi Y, Jackson T, Herold M (2018) Quantifying branch architecture of tropical trees using terrestrial LiDAR and 3D modelling. Trees. 32:1219-1231. https://doi.org/10.1007/s00468-018-1704-1

Lau A, Martius C, Bartholomeus H, Shenkin A, Jackson T, Malhi Y, Herold M, Bentley LP (2019) Estimating architecture-based metabolic scaling exponents of tropical trees using terrestrial LiDAR and 3D modelling. For Ecol Manag 439:132-145. https://doi.org/10. 1016/j.foreco.2019.02.019

Le Roux X, Lacointe A, Escobar-Gutiérrez A, Le Dizès S (2001) Carbonbased models of individual tree growth: a critical appraisal. Ann Sci 58:469-506. https://doi.org/10.1051/forest:2001140

Lehnebach R, Beyer R, Letort V, Heuret P (2018) The pipe model theory half a century on: a review. Ann Bot 121:1105-1105. https://doi.org/ 10.1093/aob/mcy031

Liang X, Kankare V, Hyyppä J, Wang Y, Kukko A, Haggrén H, Yu X, Kaartinen H, Jaakkola A, Guan F, Holopainen M, Vastaranta M (2016) Terrestrial laser scanning in forest inventories. ISPRS J Photogramm Remote Sens 115:63-77

Malhi Y, Jackson T, Patrick Bentley L, Lau A, Shenkin A, Herold M, Calders K, Bartholomeus H, Disney MI (2018) New perspectives on the ecology of tree structure and tree communities through terrestrial laser scanning. Interface Focus 8:20170052. https://doi.org/10.1098/ rsfs.2017.0052

Marquet P, Quinones R, Abades S et al (2005) Scaling and power-laws in ecological systems. J Exp Biol 208:1749-1769. https://doi.org/10. 1242/jeb.01588 
Mencuccini M, Manzoni S, Christoffersen B (2019) Modelling water fluxes in plants: from tissues to biosphere. New Phytol 0. https:// doi.org/10.1111/nph.15681

Niklas KJ (1994) Plant allometry: the scaling of form and process. University of Chicago Press

Pfeifer N, Winterhalder D (2004) Modelling of tree cross sections from terrestrial laser scanning data with free-form curves. Int Arch Photogramm Remote Sens Spat Inf Sci 36:W2

Price CA, Knox S-JC, Brodribb TJ (2013) The influence of branch order on optimal leaf vein geometries: Murray's law and area preserving branching. PLoS One 8:e85420

R Core Team (2016) R: a language and environment for statistical computing. R Foundation for Statistical Computing, Vienna https:// www.R-project.org/

Raumonen P, Kaasalainen M, Akerblom M et al (2013) Fast automatic precision tree models from terrestrial laser scanner data. Remote Sens 5:491-520. https://doi.org/10.3390/rs5020491

Shinozaki K, Yoda K, Hozumi K, Kira T (1964a) A quantitative analysis of plant form-the pipe model theory: I. Basic analyses. Jpn J Ecol 14: 97-105

Shinozaki K, Yoda K, Hozumi K, Kira T (1964b) A quantitative analysis of plant form-the pipe model theory: II. Further evidence of the theory and its application in forest ecology. Jpn J Ecol 14:133-139

Stephenson NL, Das AJ, Condit R, Russo SE, Baker PJ, Beckman NG, Coomes DA, Lines ER, Morris WK, Rüger N, Álvarez E, Blundo C, Bunyavejchewin S, Chuyong G, Davies SJ, Duque Á, Ewango CN, Flores O, Franklin JF, Grau HR, Hao Z, Harmon ME, Hubbell SP, Kenfack D, Lin Y, Makana JR, Malizia A, Malizia LR, Pabst RJ, Pongpattananurak N, Su SH, Sun IF, Tan S, Thomas D, van
Mantgem PJ, Wang X, Wiser SK, Zavala MA (2014) Rate of tree carbon accumulation increases continuously with tree size. Nature 507:90+-993. https://doi.org/10.1038/nature12914

Thies M, Pfeifer N, Winterhalder D, Gorte BG (2004) Three-dimensional reconstruction of stems for assessment of taper, sweep and lean based on laser scanning of standing trees. Scand J For Res 19: $571-581$

Tyree M, Ewers F (1991) The hydraulic architecture of trees and other woody plants. New Phytol 119:345-360. https://doi.org/10.1111/j. 1469-8137.1991.tb00035.x

Valentine H (1985) Tree-growth models - derivations employing the pipemodel theory. J Theor Biol 117:579-585. https://doi.org/10.1016/ S0022-5193(85)80239-3

Warton DI, Wright IJ, Falster DS, Westoby M (2006) Bivariate line-fitting methods for allometry. Biol Rev 81:259-291. https://doi.org/10. 1017/S1464793106007007

West GB, Brown JH, Enquist BJ (1999) A general model for the structure and allometry of plant vascular systems. Nature 400:664-667. https://doi.org/10.1038/23251

West GB, Enquist BJ, Brown JH (2009) A general quantitative theory of forest structure and dynamics. Proc Natl Acad Sci 106:7040-7045

Publisher's note Springer Nature remains neutral with regard to jurisdictional claims in published maps and institutional affiliations. 